\title{
Article \\ Effects of Virgin Microplastics on Growth, Intestinal Morphology and Microbiota on Largemouth Bass (Micropterus salmoides)
}

\author{
Chaonan Zhang ${ }^{1,2}$, Qiujie Wang ${ }^{2}$, Shaodan Wang ${ }^{2}$, Zhengkun Pan ${ }^{2}$, Di Sun ${ }^{1,2}$, Yanbo Cheng ${ }^{1}$, Jixing Zou ${ }^{2,3, *}$ \\ and Guohuan $\mathrm{Xu}$ 1,*
}

1 State Key Laboratory of Applied Microbiology Southern China, Guangdong Provincial Key Laboratory of Microbial Culture Collection and Application, Institute of Microbiology, Guangdong Academy of Sciences, Guangzhou 510070, China; zhangchaonan@stu.scau.edu.cn (C.Z.); sundi@stu.scau.edu.cn (D.S.); huaqingzq@163.com (Y.C.)

2 Joint Laboratory of Guangdong Province and Hong Kong Region on Marine Bioresource Conservation and Exploitation, College of Marine Sciences, South China Agricultural University, Guangzhou 510642, China; wongchaukit@stu.scau.edu.cn (Q.W.); 20182048005@stu.scau.edu.cn (S.W.); 20192150008@stu.scau.edu.cn (Z.P.)

3 Guangdong Laboratory for Lingnan Modern Agriculture, South China Agricultural University, Guangzhou 510642, China

* Correspondence: zoujixing@scau.edu.cn (J.Z.);wswsl@gdim.cn (G.X.)

Citation: Zhang, C.; Wang, Q.; Wang, S.; Pan, Z.; Sun, D.; Cheng, Y.; Zou, J.; $\mathrm{Xu}, \mathrm{G}$. Effects of Virgin Microplastics on Growth, Intestinal Morphology and Microbiota on Largemouth Bass (Micropterus salmoides). Appl. Sci. 2021, 11, 11921. https://doi.org/ 10.3390/app112411921

Academic Editor: Elida Nora Ferri

Received: 17 November 2021

Accepted: 7 December 2021

Published: 15 December 2021

Publisher's Note: MDPI stays neutral with regard to jurisdictional claims in published maps and institutional affiliations.

Copyright: () 2021 by the authors. Licensee MDPI, Basel, Switzerland. This article is an open access article distributed under the terms and conditions of the Creative Commons Attribution (CC BY) license (https:// creativecommons.org/licenses/by/ $4.0 /)$.

\begin{abstract}
Microplastics (MPs), classified as plastic debris less than $5 \mathrm{~mm}$ in size, are widely found in various aquatic environments. However, there have been few studies regarding their potential threat under aquaculture conditions. The aim of this study was to investigate the general health, intestinal morphology and microbiota of virgin polypropylene MPs (3-4 mm) on largemouth bass (Micropterus salmoides) over a 28-d exposure period. Four groups were divided according to whether the MPs were added in water or in food. The results disproved the hypothesis that MPs expose may adversely affect the growth of fish. Largemouth bass expelled MPs with minimal harm to the organism. MPs exposure had no significant effect on the community composition or diversity of intestinal microbial, although it could partly influence intestinal morphology, and the recombination process of the intestinal microbial community. Fish may be more sensitive to answer MPs exposure in water than in feed. Proteobacteria could potentially be pathogenic bacteria phylum in fish gut when affected by MPs. This research represents an innovative attempt to investigate the impact of virgin MPs on largemouth bass using a manipulative feeding experiment. The results could provide new insight on commercial fish health when challenged with MPs pollution.
\end{abstract}

Keywords: microplastics; largemouth bass; growth; intestinal morphology; intestinal microbiota

\section{Introduction}

Microplastics (MPs) are identified as plastic particles smaller than $5 \mathrm{~mm}$ in size as referenced by the standards setting of the US National Oceanic and Atmospheric Administration (NOAA). MPs are generally categorized in four shapes: fibers, films, fragments and spheres [1-3]. Fibers are mainly derived from textiles and worn fishing nets [4,5]. Spheres come from microbeads in beauty and health products such as cleansers [6]. Fragments and films are irregularly shaped microparticles originated from the degradation of larger plastics in the environment due to physical, chemical and biological processes [7,8]. As a potential threat to nature, MPs have appeared in nearly all environments, thus they are becoming a growing concern worldwide [9-12].

Several reviews have described how adverse effects of MPs in aquatic organisms point to important factors that lead to bioaccumulation [13-15]. Due to the attractive color, buoyancy and food-like properties, fish are particularly prone to ingesting MPs [16]. Numerous 
animal studies have shown that MPs can lead to physical damage and histopathological alterations in the intestines and can even change swimming behavior and the lipid metabolism [17-20]. We suspected that these adverse effects are generally observed in acute toxicity studies with high concentrations of MPs that may not be present in the real environment. Moreover, most MPs exposure test used regular shape microspheres as materials, while spheres were not the common shape found in MPs field investigations. The chosen concentration and shape of MPs should be reliable in the experimental design as for the caution of potential harm in aquaculture.

The definition of virgin MPs is opposite to commercial MPs. Virgin MPs mean the materials of MPs from human daily life, and generally with no uniform shape. Fibers, fragments and films, are common shapes of virgin MPs, which also commonly found in water and organisms. Few studies have reported harm to the organism coming from virgin MPs. It seems unclear whether virgin MPs cause imminent harm to fish or not, as different researchers have shown discrepant results. For example, there was no significant difference in fish mass between control group and harbor collected plastics treatment, which fed to small juvenile glassfish (Ambassis dussumieri) daily for $95 \mathrm{~d}$ [21]. Similarly, there were no significant differences in growth performance of gilthead seabream (Sparus aurata) with an experimental diet containing $500 \mathrm{mg} \mathrm{kg}^{-1}$ of PVC-MPs for $30 \mathrm{~d}$ [22]. In a related study, exposure to six common types of virgin MPs in the diet of gilthead seabream caused no observable pathology or change in growth rate [23]. Furthermore, virgin industrial MPs extracts showed no toxic effect on early life stages of Japanese medaka (Oryziaz latipes) [24]. After $45 \mathrm{~d}$ exposure period, variations in body weight and survival rate of African catfish (Clarias gariepinus) were not significantly different among the PVC-treated groups relative to the control, although fish were fed PVC MPs spiked diets at maximum 3\% [25]. However, virgin MPs altered blood biochemical parameters and changed the transcription of the reproductive-axis genes of African catfish [26]. Furthermore, researchers have also shown that marine-derived fishmeal might be a source of MPs, which could be transmitted to farmed fish, thus causing a concern in the aquaculture industry [27]. Still, the effect of virgin MPs on aquaculture is not clear.

Recently, severe MPs pollution was found in the aquaculture water of fish ponds from the Pearl River Estuary [14], which raised concerns about the safety of aquatic production. To address these concerns, this study aimed to investigate the effect of two kinds of virgin MPs on commercial fish health. We chose largemouth bass (Micropterus salmoides) as a biological model, given its key role in the Chinese fishery market as well as other important parameters, including physiological characteristics, high predation rate, and upper-middle dwelling [28,29]. The amount of Chinese production of bass was 477,808 tons in 2019 (China fishery Statistical Yearbook, 2020). The shapes of MPs in this study were restricted to fragments and fibers, since these are the most predominant shapes of MPs found in aquatic environments and in fish [3,30]. The size of MPs was 3-4 mm, and material of MPs used in this study was polypropylene, which were related to actual contamination. It was also reported that the contamination of seafood-based feeds by MPs threaten the fish health [31]. In reference to the sources of MPs that farmed fish may be exposed to, we set up two exposure ways (water and feed). The exposure concentrations of virgin MPs in water and feed were set according to previous field results [3] and study [23].

The objectives of this study were to expose largemouth bass to two shapes of virgin MPs in water and feed, finally assess their growth, intestinal morphology and microbial after four weeks. Four groups were divided according to whether the MPs were added in water or in food. We also tried to elucidate the effects of shape and exposure ways of virgin MPs on aquaculture. This research represents an innovative attempt to investigate the impact of virgin MPs on largemouth bass using a manipulative feeding experiment. 


\section{Materials and Methods}

\subsection{Experimental Fish and Culture Conditions}

Largemouth bass juvenile ( $5.64 \pm 0.6$ in length, $4.05 \pm 0.6$ in weight) were purchased from a local fishery in Shunde (Guangdong, China), and acclimatized in a circulating breeding system in South China Agricultural University (Guangzhou, China). For the acclimatization period, fish were kept in tanks $(50 \mathrm{~cm} \times 60 \mathrm{~cm} \times 60 \mathrm{~cm})$ with air-pumped circulating diluted water at least two weeks prior to the experiment. Fish were fed twice per day using commercial fish feeds (Fenghua Feed Industrial Co., Ltd., Dongguan, China) with a ratio of $5 \%$ fish body weight. Formal experiment was carried out in the same tanks with $90 \mathrm{~L}$ water and 40 largemouth bass per tank. Three experimental groups and one control group were set up with three replicates in each group, giving a total of 12 tanks and 480 fish. Weight and length information of largemouth bass are shown in Supplementary Table S1. The culture conditions during fish adaptation period were: $12 \mathrm{~h}$ light, $12 \mathrm{~h}$ dark photoperiod, dissolved oxygen concentration from 5.5 to $6.5 \mathrm{mg} / \mathrm{L}$, temperature $26 \pm 1.5^{\circ} \mathrm{C}, \mathrm{pH} 7.1$ and ammonia and nitrite levels of $0.01-0.02 \mathrm{mg} / \mathrm{L}$.

\subsection{Experimental Design and Sampling}

The materials of virgin MPs were fibers and disposable plastic cups, which were purchased from a local store (Guangzhou, China). Materials were identified through a Fourier transform infrared spectrometer (FTIR Spectrometer, Vertex 70, Bruker) and found to be polypropylene (PP) (Supplementary Figure S1). Plastic cups were cut into pieces by surgical scissors and then filtered by a $5 \mathrm{~mm}$ steel screen. These fragments made from plastic cups were 3-4 mm. The virgin fibers themselves were also 3-4 $\mathrm{mm}$ in length. The majority of microplastics (more than ninety percent) used in this study were $3-4 \mathrm{~mm}$ through measured statistically.

After, we ensured the materials, processed fragments and virgin fibers were added into fish feed; Supplementary Figure S2 shows the process of making the feed contained MPs. Specifically, the commercial feed was soaked in water to make a dough, then $0.3 \%$ weight MPs were added into the dough according to a previous protocol [21]. The feed pellets were $2-5 \mathrm{~mm}$ in size and $3.33 \mathrm{~g} / \mathrm{kg}$ of MPs in concentration, which mean there were $3.33 \mathrm{~g}$ fibers and fragments in $1 \mathrm{~kg}$ feed. Therein, $3.33 \mathrm{~g}$ MPs contained $1.665 \mathrm{~g}$ fibers and $1.665 \mathrm{~g}$ fragments. After being dried in air for $48 \mathrm{~h}$, the pellets were stored in airtight bags until use. The control group of feed was treated in the same way above, but without the addition of MPs.

The concentration of MPs set in the water was $1 \mathrm{mg} / \mathrm{L}$ at environmentally relevant level [2,3]. Fibers and fragments represented 50\%. Specifically, $90 \mathrm{~L}$ water contained $45 \mathrm{mg}$ fibers and $45 \mathrm{mg}$ fragments. MPs were thoroughly mixed in the water before fish put in. The water was refreshed every week, and MPs in water were supplemented at the same time. Fifty percent of water was changed.

Four groups were divided according to whether the MPs were added in water or in feed. In particular, MPs were found in both feed and water in Group A. MPs were found only in water and not in feed in Group B, while in Group D, MPs were found only in feed not in water. Group $C$ is the control group, and there was no MPs in feed or water.

The fish were cultured for $28 \mathrm{~d}$ in such setting groups, starting from 28 June 2020 . The culture conditions were: $12 \mathrm{~h}$ light, $12 \mathrm{~h}$ dark photoperiod, dissolved oxygen concentration from 5.3 to $6.8 \mathrm{mg} / \mathrm{L}$, temperature $26.2 \pm 1.3{ }^{\circ} \mathrm{C}, \mathrm{pH} 6.8-7.2$, and ammonia and nitrite levels of $0.01-0.02 \mathrm{mg} / \mathrm{L}$. Fish were fed feed of $5 \%$ body mass twice per day in the regular feeding time (9:00, 17:00). During cultivation, the health condition of fish in each group was observed and recorded every day. Dead fish was removed from the tank as soon as possible. At the end of the experiment, 10 fish were randomly selected from each tank for euthanasia with 3-aminobenzoic acid ethyl ester methane sulfonate (MS-222) (50 mg/L) (Adamas-beta, Shanghai, China). The middle part of intestinal specimens was dissected from anaesthetized fish, placed in $1.5 \mathrm{~mL}$ sterile centrifuge tubes and stored in $-80^{\circ} \mathrm{C}$ for the microbial assay. The process was repeated five times with fifteen samples in each group. 
The other five intestinal specimens were removed, and fixed in paraformaldehyde fixing solution (Servicebio, Wuhan, China) for histopathology analyses. This study was carried out in strict accordance with the recommendations in the Guide for the Care and Use of Laboratory Animals of the National Institutes of Health. The protocol was according to the National Institute of Health Guide for the Care and Use of Laboratory Animals of China. All experiments were approved by the Animal Care and Use Committee of South China Agricultural University (identification code: 20200127; date of approval: 20 May 2020). All surgery was performed under anesthesia with MS-222, and all efforts were made to minimize suffering.

\subsection{Growth Performance}

Body weight and length of five fish from the different groups were measured before and after the trial. Growth was measured by obtaining the weight gain $(\mathrm{WG} \%)$ and specific growth rate (SGR) according to [22].

$$
\begin{aligned}
& \text { WG\% }=(\text { final weight }- \text { initial weight }) \times 100 / \text { initial weight. } \\
& \text { SGR }=[(\text { Ln }(\text { final weight })-\text { Ln (initial weight })) \times 100] / \text { days. }
\end{aligned}
$$

\subsection{Intestinal Histopathology}

Fixed intestinal samples were processed by standard methods by placing into paraffin blocks, cutting at $5 \mu \mathrm{m}$, and staining with hematoxylin and eosin (H and E). Tissue sections were examined with a microscope (Nikon, Tokyo, Japan) and photographed using the Mshot Image Analysis System. The intestinal folds length was measured from basement to top of the intestinal folds in each group.

\subsection{Intestinal Microbial Assay}

The five intestinal specimens in each group were mixed for the microbial assay. Each group had three repeats. Microbial DNA was extracted from intestine samples using the E.Z.N.A. ${ }^{\circledR}$ soil DNA Kit (Omega Bio-tek, Norcross, GA, USA) according to the manufacturer's protocols. Specific steps of PCR reactions are presented in Supporting Text S1. Purified amplicons were reacted on the Illumina MiSeq platform (Illumina, San Diego, CA, USA) according to the standard protocols provided by Majorbio Bio-Pharm Technology Co. Ltd. (Shanghai, China). Processing of raw fastq files is presented in Supporting Text S2. The Kruskal-Wallis test was used to compare the difference among groups.

\subsection{Statistical Analysis}

All data were quantified as the mean \pm standard deviation (SD). One-way analysis of variance (ANOVA) and Duncan's multiple range test was performed via the $\mathrm{R}$ program (V5.1.3) (Development Core Team, 2018), SPSS 17.0 statistical package (SPSS Inc., Chicago, IL, USA). GraphPad Prism 7 (GraphPad Software, San Diego, CA, USA) were used to assess the differences among different groups. Differences were considered significant at $p<0.05$ and highly significant at $p<0.01$. Intestinal microbial analyses are shown in Supporting Text S3.

\section{Results}

\subsection{Growth Performance}

During the manipulative feeding experiments, largemouth bass readily consumed the different feed and showed the similar feeding behavior. The survival rate of each group was above $90 \%$, and there was no significant difference (Group A: $92.5 \%$; Group B: $95 \%$; Group C: $90 \%$; and Group D: $92.5 \%$ ). At the end of the trial, no significant differences were detected in WG\% or SGR among the different groups of largemouth bass (Figure 1). Weight and length information of largemouth bass is presented in Supplementary Table S1. 


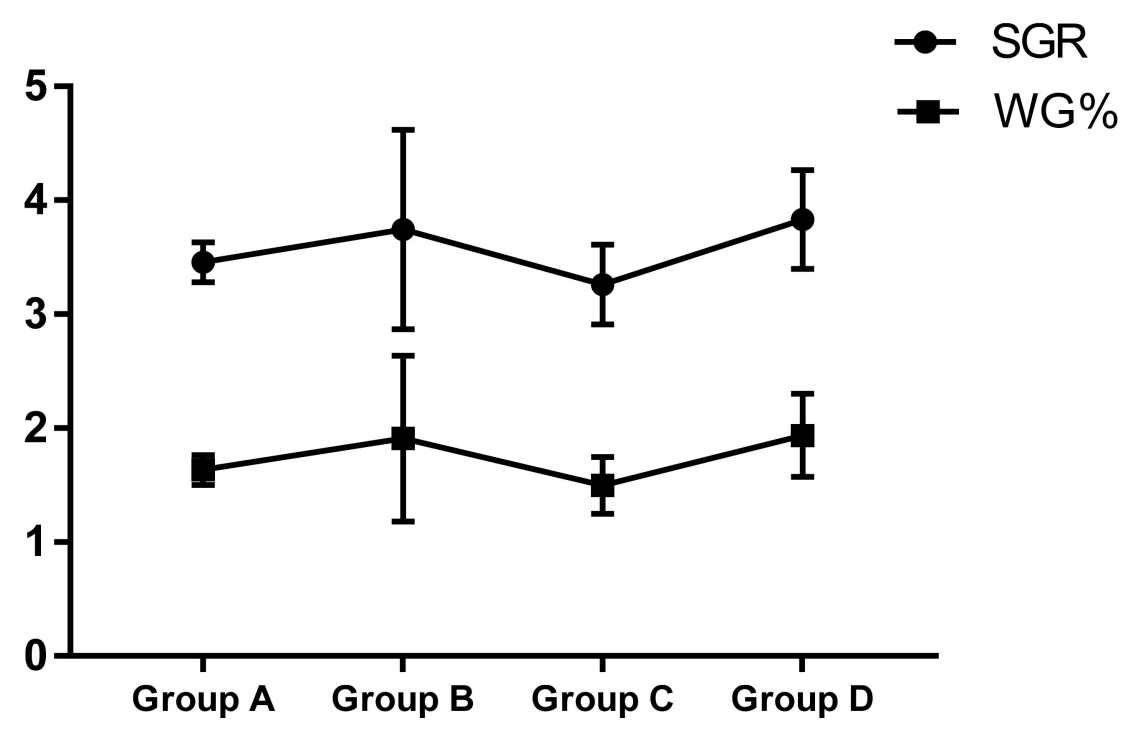

Figure 1. SGR and WG\% of largemouth bass among each group after the trial.

\subsection{Intestinal Histopathology}

The intestinal histomorphology of largemouth bass among each group was observed by microscopy (Figure 2). Fish in the control group had normal intestinal wall morphology and a smooth epithelial layer (Figure 2C). However, a variety of intestinal abnormalities were found in the MPs treatment group. The folds of the intestine were irregularly arranged, and exfoliation of tissue to varying degrees were found in the intestinal folds (Figure 2A,B,D). The degree of intestinal damage was similar in all MPs treatment groups. However, there was no statistically significant difference in the intestinal folds length among the groups (Supplementary Figure S3).
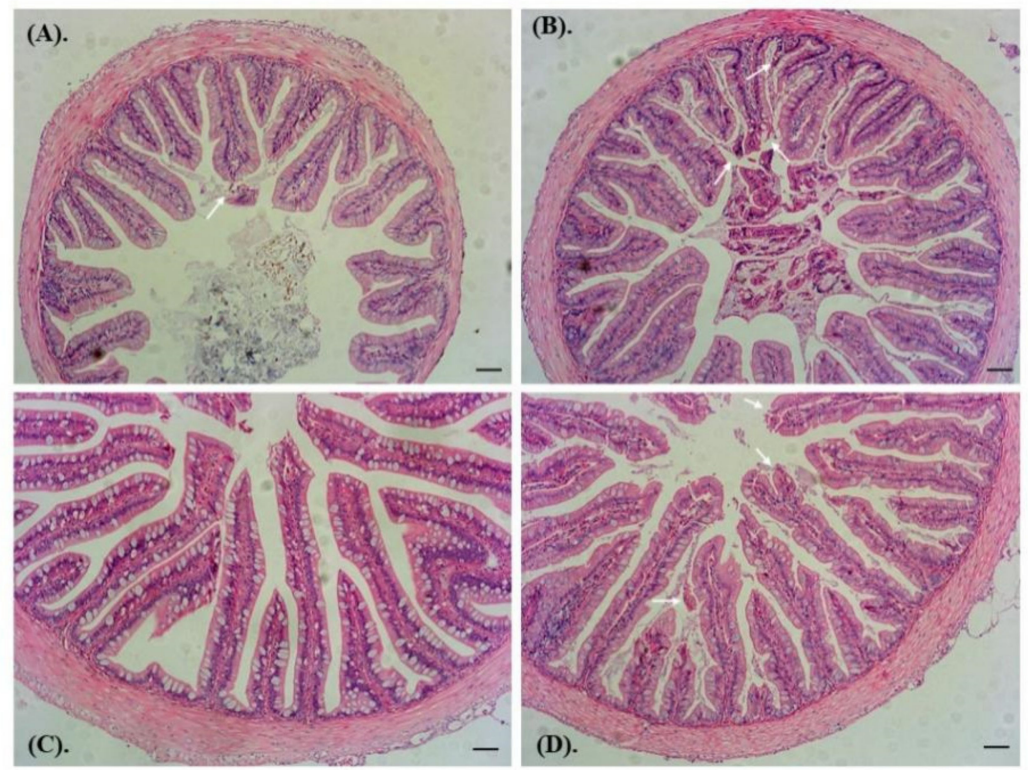

Figure 2. The intestine morphology of largemouth bass in Group A (A), Group B (B), Group C (C) and Control group D (D). Scale bar $=50 \mu \mathrm{m}$. White arrow indicates the location of the lesion.

\subsection{Intestinal Microbiota Diversity}

The intestinal microbial compositions in largemouth bass in four groups were investigated in this study. A total of 726,114 high quality sequences were retrieved from 
12 samples (three repetitions in each group) belonging to four study groups. The saturation plateau of the rarefaction curves was well established (Supplementary Figure S4), indicating that this study covered nearly all the microbial diversity. According to the results of Good's coverage estimator, the microorganisms obtained from the 12 samples reached $100 \%$. All matching tags were divided into 1428 OTUs, with $97 \%$ tagging similarity values. Venn of OTUs in each group showed Group A and B had independent 201 and 211 OTUs, respectively, while Group C and D only had 64 and 72 OTUs (Figure 3). MPs in water may be the major factor in restructuring the intestinal microbial composition.

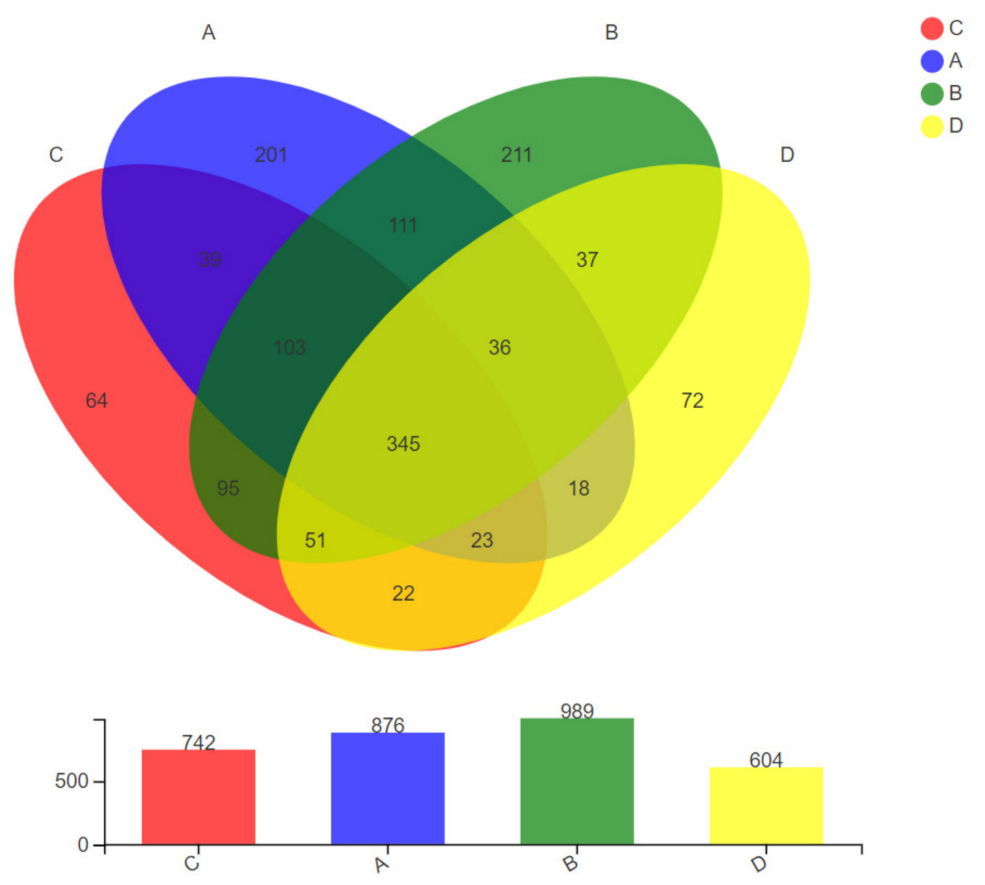

Figure 3. Venn of OTUs in each group.

The $\alpha$-diversities of the intestinal microbiota sequencing completeness in each group were determined by the community richness index (Chao, Ace) and community diversity index (Simpson, Shannon), that are shown in Supplementary Table S2. There was no significant difference between Group A, B, C or D analyzed with a $t$-test (Figure 4), which demonstrated that the diversity of intestinal microbes in largemouth bass was not changed when exposure to MPs occurred in different ways.

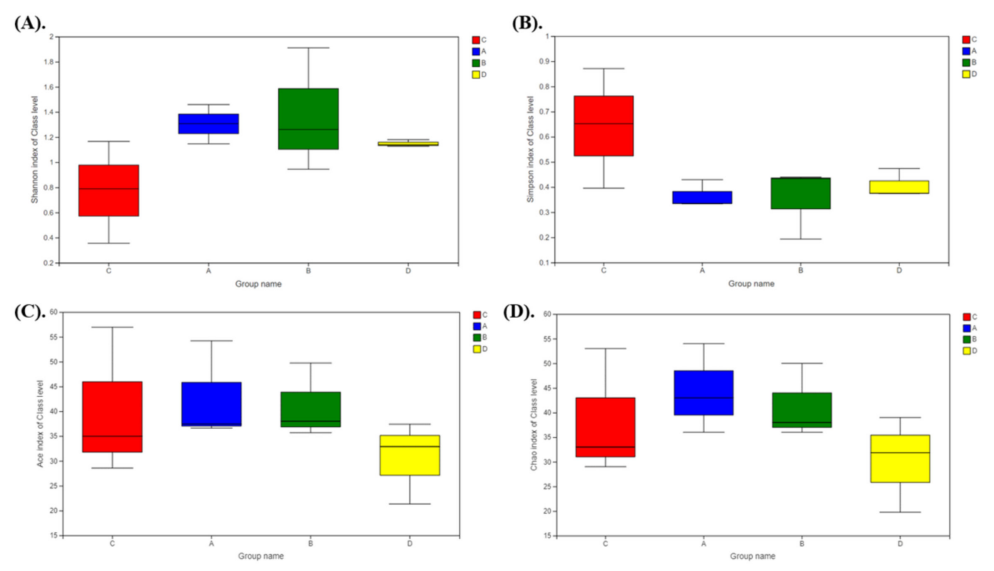

Figure 4. Box plots of intestinal microbiota diversity and richness in largemouth bass among each group after trial. (A) Shannon index of class level; (B) Simpson index of class level; (C) Ace index of class level; (D) Chao index of class level. 


\subsection{Intestinal Microbial Community Structures at Phylum and Genus Taxonomic Level}

Bacterial compositions of the different communities and results of the Kruskal-Wallis test for differences in these microbial taxa among each group at the phylum level are shown in Figure 5. The dominant Phyla among the four groups were Firmicutes, Proteobacteria and Fusobacteriota (Figure 5A). The relative abundance of Proteobacteria and Actinobacteria gradually increased compared with the control group, but there was no significant difference among each group based on the Kruskal-Wallis test (Figure 5B). Intestinal microbial compositions at the genus level were also detected (Figure 6). The dominant genera in the gut of largemouth bass were Mycoplasma, Cetobacterium and Plesiomonas (Figure 6A). Therein, the percentage of Mycoplasma in intestinal microbial composition was the highest in healthy largemouth bass $(70 \%)$, while the proportion of Mycoplasma in virgin MPs treatment groups was under $40 \%$. The relative abundance of Cetobacterium in Group A gradually decreased, while Blautia increased compared with the control group. However, there was no significant effect on the microbial community composition at the genus level among each group statistically (Figure 6B).
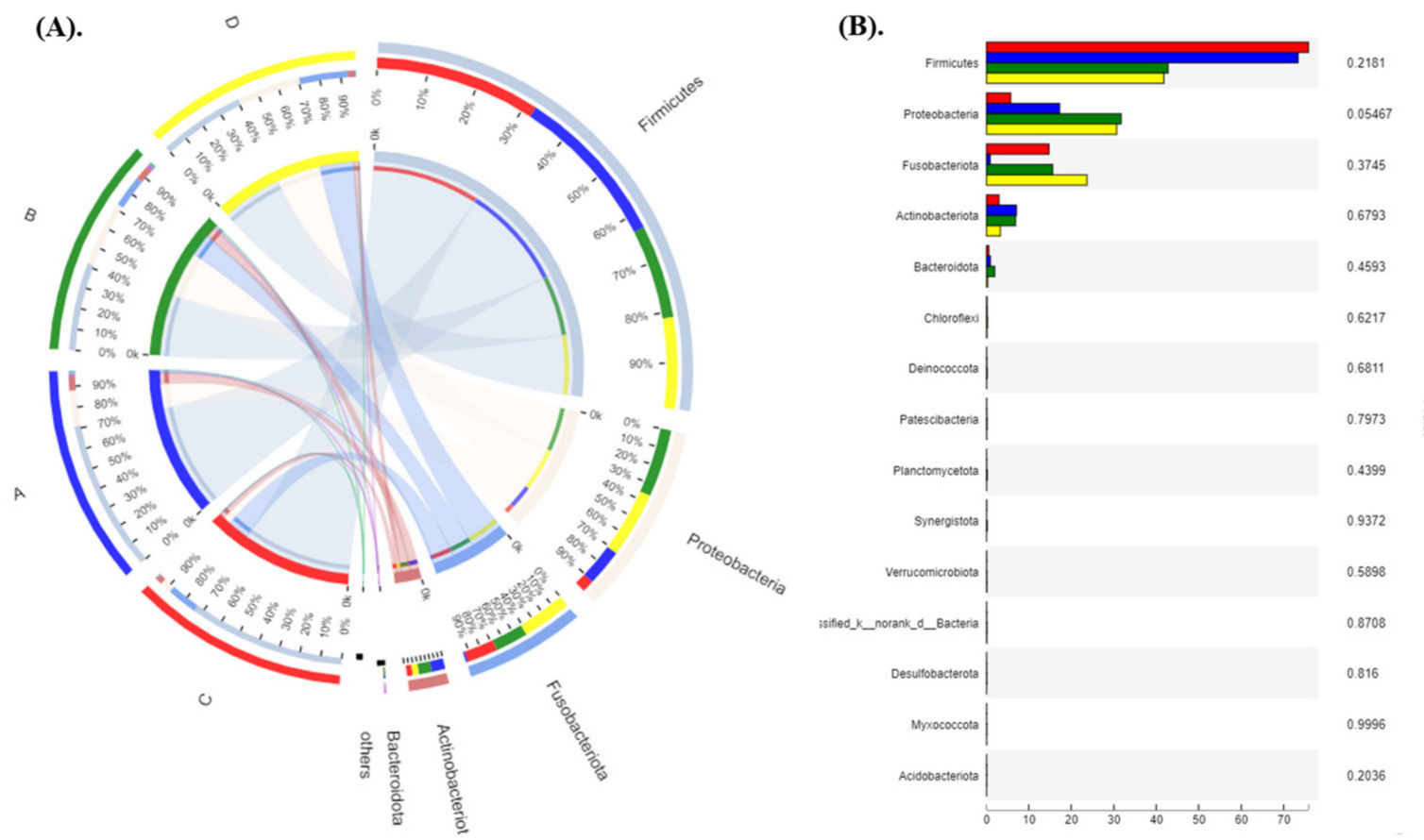

Figure 5. Bacterial compositions of the different communities (A) and results of the Kruskal-Wallis test for differences in these microbial taxa (B) among each group at the phylum level.

Principal coordinate analysis (PCA) based on the unweighted UniFrac scores of the microbial communities was performed to reflect the differences and distances between microbes among each group. The results showed that the largemouth bass in three MPs treatment groups (A, B and D) possessed similar compositions of microbes, while the fish in the control group was different from the experimental groups (Figure 7). Virgin MPs exposure could partly influence the recombination process of the intestinal microbial community. 


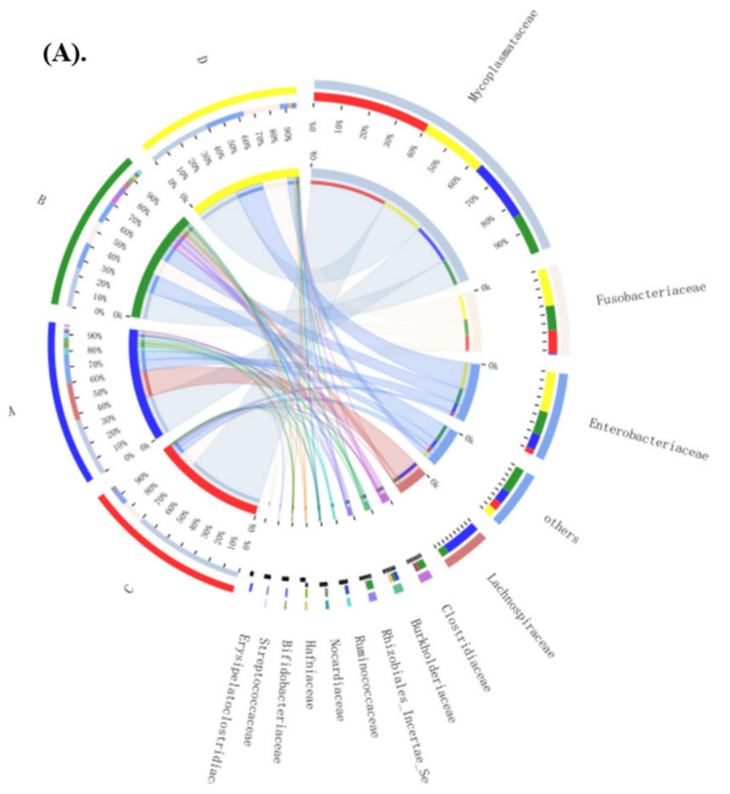

(B).

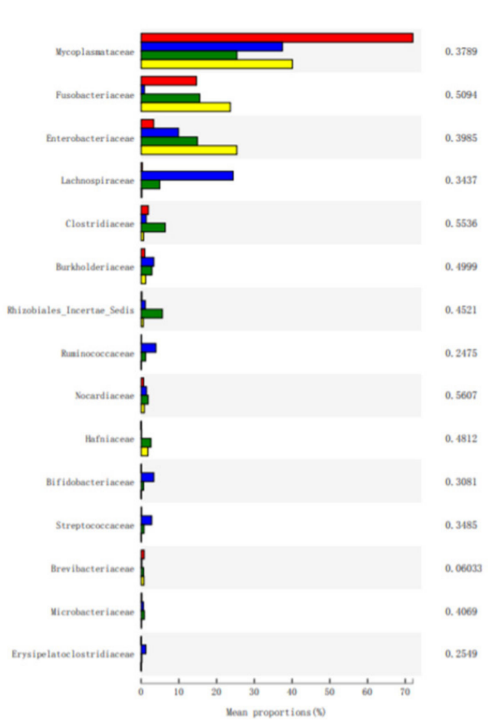

름

Figure 6. Bacterial compositions of the different communities (A) and results of the Kruskal-Wallis test for differences in these microbial taxa (B) among each group at the genus level.

\section{PCA on OTU level}

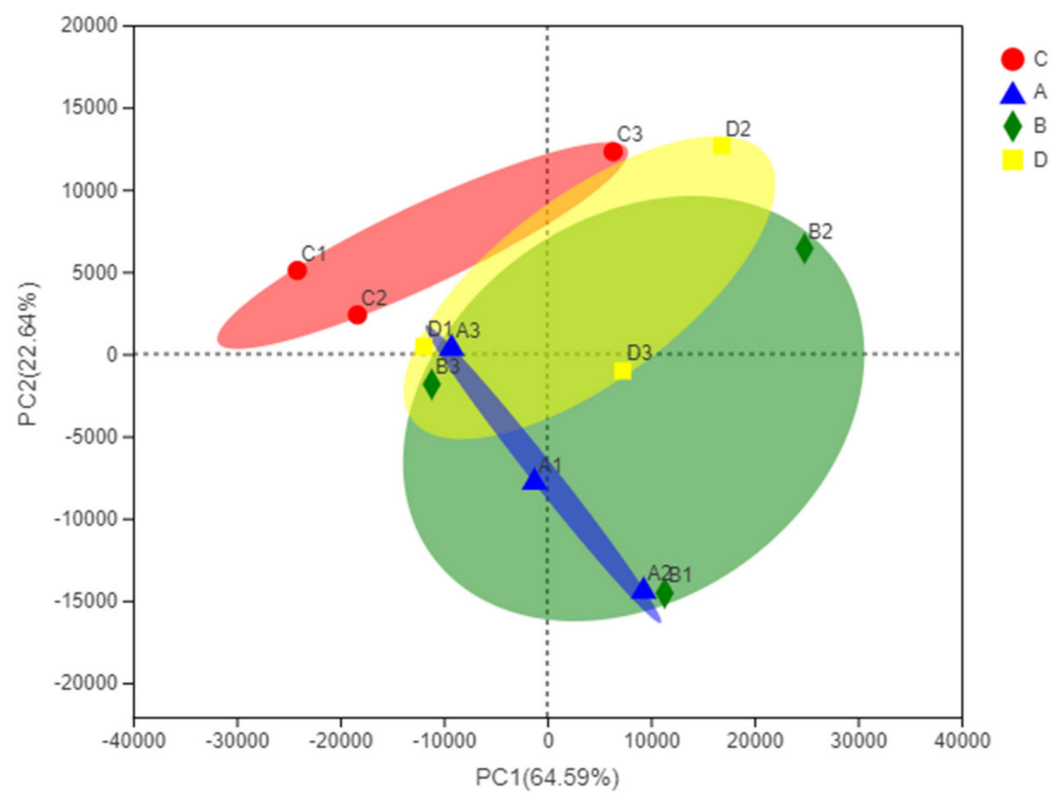

Figure 7. Principal coordinate analysis (PCA) on OTU level among each group.

\section{Discussion}

\subsection{The Exposure Condition of MPS}

Taking the shape and size of MPs into consideration, there are several problems in the existing literature that report the effects of MPs on aquatic organisms. For example, there is a wide range of polymer sizes reported in the literature, but more of a homogeneous shape used (i.e., microbeads) [32]. It is possible that the millimeter-sized MPs might be excreted more quickly by the organism [20]. The middle part of the gut of largemouth bass was examined after the feeding experiment. Nearly no MPs residue was found in any group. Our results were similar with Jabeen et al., (2018), which they found little MPs residue in goldfish intestine since the fish chewed fragments and pellets and then expelled them [33]. 
Exposure to MPs has been proven as having negative effects on various aspects of aquatic organisms, such as growth, behavior, development, reproduction and even death [13-15]. However, the experimental setup in which organisms were exposed to excessive concentration of MPs, far exceeds the native concentration in aquatic environments. However, in the present study, $1 \mathrm{mg} / \mathrm{L}$ was set as the water MPs concentration, and $0.3 \%$ of the total daily feed as the feed MPs concentration [2,3,21]. The ingested MPs content by fish per day could not exceed this setting, even in aquatic environments with a high MPs concentration. In addition, juvenile fish are more susceptible to environmental disturbances than adult fish [34]; therefore, juvenile fish may be more vulnerable to MPs treatment [21]. However, virgin MPs were not causing imminent harm to largemouth bass juveniles after dietary or water exposure.

\subsection{Effect of MPs on Fish Growth}

It is generally accepted that MPs would decrease fish body length or weight, since the ingestion of MPs might increase the energy burden on organisms and decrease energy reserves through the catalysis of lipids [35]. Specifically, the MPs-treated fish possibly have to redirect energy used for growth toward other important functions, such as systemic removal and detoxification of the MPs in the body [21]. Energy is also required to cope with other stresses, such as inflammation and a compromised endocrine system, burdened liver detox function and aberrant food absorption.

The hypothesis stating that exposure to virgin MPs adversely effects fish growth was not supported by the data in our study. After four weeks, the treatment fish did not show lower growth in length or body weight compared to controls. Growth index is one of the most important parameters that is measured in aquaculture. While the results presented here may provide an optimistic outlook for the aquaculture industry, laboratory results may not reflect the true situation in aquaculture where there are many other environmental factors (i.e., antibiotics, heavy metals and hormones). Although there are papers where microplastics did not show any effect on fish growth [36,37], and there are also a lot of studies showing retarded growth of fish [21,38]. This topic very much depends on fish species, microplastic shape and size, behavior and feeding habits of fish, etc. Further research is needed on the combined toxicity of MPs and other environmental contaminants.

\subsection{Effect of MPs on Fish Intestinal Morphology}

In this study, virgin MPs caused structural damage to intestines of largemouth bass, although we didn't find residual MPs in the microphotographs or statistically significance in the intestinal folds length among the groups. It was reported that morphological measurements of the intestinal folds length could help predict the absorption and digestion mechanisms of the fish intestinal tract [39]. The shortening of intestinal folds may be related to the toxin stress [40]. Fish intestinal abnormalities were found in many MPs toxic studies; however, statistically significant differences were rarely found in the data. For example, tissue morphology of rainbow trout (Oncorhynchus mykiss) did not change after dietary exposure to MPs for 4 weeks through qualitative histological examination of different intestinal segments [41]. The histopathology scores for leukocyte infiltration in the intestine of gilthead seabream with six virgin MPs for $45 \mathrm{~d}$ were not significantly different [23]. No tissue damage was found in silver barb (Barbodes gonionotus) fry internal organs or gills when exposed to polyvinyl chloride (PVC) fragments because of their relatively smooth surface [42]. Differences in pathological statistics might require longer experimental period and observation of specific tissue parts. Pedà et al., (2016) found the distal part of intestine had mostly been affected by pathological alterations after $90 \mathrm{~d}$ of exposure [43]. Pathological changes are generally descriptive, reflecting characteristics through comparison with the control group, but there are individual differences that require more research. 


\subsection{Effect of MPs on Fish Intestinal Microbiota}

In this study, diversity or composition of intestinal microbiota was not significantly changed by virgin MPs exposure. However, PCA analysis revealed that MPs in water shaped the bacterial community composition by separating Group A and B from the control group. The relative abundance of Proteobacteria and Actinobacteria gradually increased compared with the control group at the phylum level. The dominant genera in the gut of largemouth bass were Mycoplasma in healthy largemouth bass, while they were decreased after MPs treatment. Huang et al., (2020) also found the gut microbiota in juvenile guppy (Poecilia reticulata) were dominated by Proteobacteria and Actinobacteria, and exposure to MPs resulted in an increase of Proteobacteria at phylum level [44]. Similar results were found in zebrafish gut, Proteobacteria significantly decreased $(p<0.05)$ after exposure to $5 \mu \mathrm{m}$ microbeads for $21 \mathrm{~d}$ [45]. Proteobacteria were more prevalent in contaminated environments with higher MPs concentrations [46]. The growth of Proteobacteria and other bacteria were encouraged by the inflammation induced oxidation that connected with microbiota dysbiosis [47]. Collectively, Proteobacteria could potentially be pathogenic bacteria phylum in fish gut when affected by MPs.

Moreover, the general resilience of fish intestinal microbiota was found in a study of common carp (Cyprinus carpio) exposed to environmentally relevant concentrations of MPs for $30 \mathrm{~d}$ and followed by MPs excretion for another $30 \mathrm{~d}$ [48]. We tried to use experiments to simulate real aquacultural situations and found that the fish themselves can cope with the pressure of MPs more than our expectation. Nevertheless, we should also acknowledge that the absence of biofilm can be advantageous in reducing the variables that can affect the gut microbiological diversity, thus simplifying the interpretation of the results.

\section{Conclusions}

There are growing concerns about the potential toxic effects of MPs on aquatic organisms. These toxic pollutants may have far-reaching disadvantages on the aquaculture industry and on human health. This study offered new insight about the effect of virgin polypropylene MPs (3-4 mm) on commercial fish health. Firstly, the results presented here do not support the hypothesis that the addition of MPs has an adverse effect on fish growth. After a four-week trial, the body length and weight of the treatment largemouth bass were indistinguishable from the control group. Secondly, MPs exposure had no significant effect on the community composition or diversity of intestinal microbial, although it could partly influence intestinal morphology, and the recombination process of the intestinal microbial community. Virgin MPs did not cause imminent harm to largemouth bass. However, the results only offer temporary relief, since pollutants in the natural environment are more complex. We used MPs that were brand new. There were no weathering effects or biofilm on their smooth surface. This is unrealistic for natural pond MPs pollution. Furthermore, the choice of size and polymer of MPs affects the results. More attention should be addressed on combined toxicity of MPs and other contaminants in further research.

Supplementary Materials: The following are available online at https://www.mdpi.com/article/ 10.3390/app112411921/s1, Table S1: Weight and length information of largemouth bass before and after the experiment; Table S2: Alpha diversity of intestinal microbiota; Figure S1: Identification of materials; Figure S2: The process of making fodder contained MPs; Figure S3: Villi length of largemouth bass among each group after the trial; Figure S4: Rarefaction curves; Supporting Text S1: Specific steps of PCR reactions; Supporting Text S2: Processing of raw fastq files; Supporting Text S3: Intestinal microbial analyses.

Author Contributions: Conceptualization, C.Z. and G.X.; methodology, S.W. and Z.P.; software, Q.W.; validation, J.Z., Q.W. and S.W.; formal analysis, C.Z.; investigation, D.S. and Y.C.; resources, J.Z.; data curation, Q.W.; writing—original draft preparation, C.Z.; writing—review and editing, G.X.; visualization, J.Z.; supervision, G.X.; project administration, J.Z.; funding acquisition, G.X. All authors have read and agreed to the published version of the manuscript. 
Funding: This research was funded by the Key Realm R\&D Program of Guangdong Province (No. 2020B0202080005), and China Agriculture Research System of MOF and MARA (CARS-45-50).

Institutional Review Board Statement: The study was conducted according to the Animal Care and Use Committee of South China Agricultural University (identification code: 20200127; date of approval: 20 May 2020).

Informed Consent Statement: Informed consent was obtained from all subjects involved in the study. Written informed consent has been obtained from the patient(s) to publish this paper.

Data Availability Statement: The data presented in this study are available on request from the corresponding author.

Conflicts of Interest: The authors report no conflict of interest.

\section{References}

1. Hidalgo-Ruz, V.; Gutow, L.; Thompson, R.C.; Thiel, M. Microplastics in the marine environment: A review of the methods used for identification and quantification. Environ. Sci. Technol. 2012, 46, 3060-3075. [CrossRef]

2. Jabeen, K.; Su, L.; Li, J.; Yang, D.; Tong, C.; Mu, J.; Shi, H. Microplastics and mesoplastics in fish from coastal and fresh waters of China. Environ. Pollut. 2017, 221, 141-149. [CrossRef]

3. Zhang, C.; Wang, S.; Sun, D.; Pan, Z.; Zhou, A.; Xie, S.; Wang, J.; Zou, J. Microplastic pollution in surface water from east coastal areas of Guangdong, South China and preliminary study on microplastics biomonitoring using two marine fish. Chemosphere 2020, 256, 127202. [CrossRef] [PubMed]

4. Hernandez, E.; Nowack, B.; Mitrano, D.M. Polyester Textiles as a Source of Microplastics from Households: A Mechanistic Study to Understand Microfiber Release During Washing. Environ. Sci. Technol. 2017, 51, 7036-7046. [CrossRef]

5. Feng, Z.; Zhang, T.; Li, Y.; He, X.; Wang, R.; Xu, J.; Gao, G. The accumulation of microplastics in fish from an important fish farm and mariculture area, Haizhou Bay, China. Sci. Total Environ. 2019, 696, 133948. [CrossRef]

6. Mcdevitt, J.P.; Criddle, C.S.; Morse, M.; Hale, R.C.; Bott, C.B.; Rochman, C.M. Addressing the Issue of Microplastics in the Wake of the Microbead-Free Waters Act-A New Standard Can Facilitate Improved Policy. Environ. Sci. Technol. 2017, 51, 6611-6617. [CrossRef] [PubMed]

7. Zbyszewski, M.; Corcoran, P.L. Distribution and Degradation of Fresh Water Plastic Particles Along the Beaches of Lake Huron, Canada. Water Air Soil Pollut. 2011, 220, 365-372. [CrossRef]

8. Alimi, O.S.; Farner, B.J.; Hernandez, L.M.; Tufenkji, N. Microplastics and Nanoplastics in Aquatic Environments: Aggregation, Deposition, and Enhanced Contaminant Transport. Environ. Sci. Technol. 2018, 52, 1704-1724. [CrossRef]

9. Wright, S.L.; Kelly, F.J. Plastic and Human Health: A Micro Issue? Environ. Sci. Technol. 2017, 51, 6634-6647. [CrossRef] [PubMed]

10. Prata, J.C.; Da, C.J.; Lopes, I.; Duarte, A.C.; Rocha-Santos, T. Environmental exposure to microplastics: An overview on possible human health effects. Sci. Total Environ. 2020, 702, 134455. [CrossRef]

11. Wang, W.; Ge, J.; Yu, X.; Li, H. Environmental fate and impacts of microplastics in soil ecosystems: Progress and perspective. Sci. Total Environ. 2020, 708, 134841. [CrossRef] [PubMed]

12. Zhou, A.; Zhang, Y.; Xie, S.; Chen, Y.; Li, X.; Wang, J.; Zou, J. Microplastics and their potential effects on the aquaculture systems: A critical review. Rev. Aquacult. 2021, 13, 719-733. [CrossRef]

13. Jacob, H.; Besson, M.; Swarzenski, P.W.; Lecchini, D.; Metian, M. Effects of Virgin Micro- and Nanoplastics on Fish: Trends, Meta-Analysis, and Perspectives. Environ. Sci. Technol. 2020, 54, 4733-4745. [CrossRef]

14. Ma, J.; Niu, X.; Zhang, D.; Lu, L.; Ye, X.; Deng, W.; Li, Y.; Lin, Z. High levels of microplastic pollution in aquaculture water of fish ponds in the Pearl River Estuary of Guangzhou, China. Sci. Total Environ. 2020, 744, 140679. [CrossRef] [PubMed]

15. Xu, S.; Ma, J.; Ji, R.; Pan, K.; Miao, A.J. Microplastics in aquatic environments: Occurrence, accumulation, and biological effects. Sci. Total Environ. 2020, 703, 134699. [CrossRef] [PubMed]

16. Garrido, G.E.; Ryder, J.; Elvevoll, E.O.; Olsen, R.L. Microplastics in Fish and Shellfish-A Threat to Seafood Safety? J. Aquat. Food Prod. T. 2020, 29. [CrossRef]

17. Lei, L.; Wu, S.; Lu, S.; Liu, M.; Song, Y.; Fu, Z.; Shi, H.; Raley-Susman, K.M.; He, D. Microplastic particles cause intestinal damage and other adverse effects in zebrafish Danio rerio and nematode Caenorhabditis elegans. Sci. Total Environ. 2018, 619-620, 1-8. [CrossRef] [PubMed]

18. Gu, H.; Wang, S.; Wang, X.; Yu, X.; Hu, M.; Huang, W.; Wang, Y. Nanoplastics impair the intestinal health of the juvenile large yellow croaker Larimichthys crocea. J. Hazard. Mater. 2020, 397, 122773. [CrossRef]

19. Liyun, Y.; Haiyan, L.; Hongwu, C.; Bijuan, C.; Lingli, L.; Fan, W. Impacts of polystyrene microplastics on the behavior and metabolism in a marine demersal teleost, black rockfish (Sebastes schlegelii). J. Hazard. Mater. 2019, 380, 120861.

20. Hirt, N.; Body-Malapel, M. Immunotoxicity and intestinal effects of nano- and microplastics: A review of the literature. Part. Fibre Toxicol. 2020, 17, 57. [CrossRef]

21. Naidoo, T.; Glassom, D. Decreased growth and survival in small juvenile fish, after chronic exposure to environmentally relevant concentrations of microplastic. Mar. Pollut. Bull. 2019, 145, 254-259. [CrossRef] 
22. Cristóbal, E.; Alberto, C.; María, Á.E. Effects of dietary polyvinylchloride microparticles on general health, immune status and expression of several genes related to stress in gilthead seabream (Sparus aurata L.). Fish Shellfish Immunol. 2017, 68, 251-259.

23. Jovanovic, B.; Gokdag, K.; Guven, O.; Emre, Y.; Whitley, E.M.; Kideys, A.E. Virgin microplastics are not causing imminent harm to fish after dietary exposure. Mar. Pollut. Bull. 2018, 130, 123-131. [CrossRef] [PubMed]

24. Pauline, P.; Bénédicte, M.; Christelle, C.; Jennifer, L.; Coline, C.; Jérôme, C. Toxicity assessment of pollutants sorbed on environmental microplastics collected on beaches: Part II-adverse effects on Japanese medaka early life stages. Environ. Pollut. 2019, 248, 1098-1107.

25. Stanley, C.I.; Gregory, E.O. Dietary exposure to polyvinyl chloride microparticles induced oxidative stress and hepatic damage in Clarias gariepinus (Burchell, 1822). Environ. Sci. Pollut. Res. 2020, 27, 21159-21173.

26. Karami, A.; Romano, N.; Galloway, T.; Hamzah, H. Virgin microplastics cause toxicity and modulate the impacts of phenanthrene on biomarker responses in African catfish (Clarias gariepinus). Environ. Res. 2016, 151, 58-70. [CrossRef] [PubMed]

27. Hanachi, P.; Karbalaei, S.; Walker, T.R.; Cole, M.; Hosseini, S.V. Abundance and properties of microplastics found in commercial fish meal and cultured common carp (Cyprinus carpio). Environ. Sci. Pollut. Res. 2019, 26, 23777-23787. [CrossRef]

28. Nicholas, R.; Nathan, E.; Herbert, Q.; Anita, K.; Amit, K.S. The effects of water hardness on the growth, metabolic indicators and stress resistance of largemouth bass Micropterus salmoides. Aquaculture 2020, 527, 735469.

29. Wang, Y.; Ni, J.; Nie, Z.; Gao, J.; Sun, Y.; Shao, N.; Li, Q.; Hu, J.; Xu, P.; Xu, G. Effects of stocking density on growth, serum parameters, antioxidant status, liver and intestine histology and gene expression of largemouth bass (Micropterus salmoides) farmed in the in-pond raceway system. Aquac. Res. 2020, 51, 5228-5240. [CrossRef]

30. Wang, S.; Zhang, C.; Pan, Z.; Sun, D.; Zhou, A.; Xie, S.; Wang, J.; Zou, J. Microplastics in wild freshwater fish of different feeding habits from Beijiang and Pearl River Delta regions, south China. Chemosphere 2020, 258, 127345. [CrossRef]

31. Yao, C.; Liu, X.; Wang, H.; Sun, X.; Qian, Q.; Zhou, J. Occurrence of Microplastics in Fish and Shrimp Feeds. Bull. Environ. Contam. Toxicol. 2021, 107, 684-692. [CrossRef]

32. Phuong, N.N.; Zalouk-Vergnoux, A.; Poirier, L.; Kamari, A.; Châtel, A.; Mouneyrac, C.; Lagarde, F. Is there any consistency between the microplastics found in the field and those used in laboratory experiments? Environ. Pollut. 2016, 211, 111-123. [CrossRef]

33. Jabeen, K.; Li, B.; Chen, Q.; Su, L.; Wu, C.; Hollert, H.; Shi, H. Effects of virgin microplastics on goldfish (Carassius auratus). Chemosphere 2018, 213, 323-332. [CrossRef]

34. Lima, A.R.A.; Barletta, M.; Costa, M.F.; Ramos, J.A.A.; Dantas, D.V.; Melo, P.A.M.C.; Justino, A.K.S.; Ferreira, G.V.B. Changes in the composition of ichthyoplankton assemblage and plastic debris in mangrove creeks relative to moon phases. J. Fish Biol. 2016, 89, 619-640. [CrossRef] [PubMed]

35. Ouyang, M.Y.; Liu, J.H.; Wen, B.; Huang, J.N.; Feng, X.S.; Gao, J.Z.; Chen, Z.Z. Ecological stoichiometric and stable isotopic responses to microplastics are modified by food conditions in koi carp. J. Hazard. Mater. 2021, 404, 124121. [CrossRef] [PubMed]

36. Critchell, K.; Hoogenboom, M.O. Effects of microplastic exposure on the body condition and behaviour of planktivorous reef fish (Acanthochromis polyacanthus). PLoS ONE 2018, 13, e193308. [CrossRef] [PubMed]

37. Malinich, T.D.; Chou, N.; Sepúlveda, M.S.; Höök, T.O. No evidence of microplastic impacts on consumption or growth of larval Pimephales promelas. Environ. Toxicol. Chem. 2018, 37, 2912-2918. [CrossRef] [PubMed]

38. Xia, X.; Sun, M.; Zhou, M.; Chang, Z.; Li, L. Polyvinyl chloride microplastics induce growth inhibition and oxidative stress in Cyprinus carpio var. larvae. Sci. Total Environ. 2020, 716, 136479. [CrossRef]

39. Dawood, M.A.O.; Eweedah, N.M.; Khalafalla, M.M.; Khalid, A.; Asely, A.E.; Fadl, S.E.; Amin, A.A.; Paray, B.A.; Ahmed, H.A. Saccharomyces cerevisiae increases the acceptability of Nile tilapia (Oreochromis niloticus) to date palm seed meal. Aquac. Rep. 2019, 17, 100314. [CrossRef]

40. Tan, X.; Sun, Z.; Zhou, C.; Huang, Z.; Tan, L.; Xun, P.; Huang, Q.; Lin, H.; Ye, C.; Wang, A. Effects of dietary dandelion extract on intestinal morphology, antioxidant status, immune function and physical barrier function of juvenile golden pompano Trachinotus ovatus. Fish Shellfish Immunol. 2018, 73, 197-206. [CrossRef]

41. Asmonaite, G.; Sundh, H.; Asker, N.; Almroth, B.C. Rainbow Trout Maintain Intestinal Transport and Barrier Functions Following Exposure to Polystyrene Microplastics. Environ. Sci. Technol. 2018, 52, 14392-14401. [CrossRef]

42. Romano, N.; Ashikin, M.; Teh, J.C.; Syukri, F.; Karami, A. Effects of pristine polyvinyl chloride fragments on whole body histology and protease activity in silver barb Barbodes gonionotus fry. Environ. Pollut. 2018, 237, 1106-1111. [CrossRef] [PubMed]

43. Pedà, C.; Caccamo, L.; Fossi, M.C.; Gai, F.; Andaloro, F.; Genovese, L.; Perdichizzi, A.; Romeo, T.; Maricchiolo, G. Intestinal alterations in European sea bass Dicentrarchus labrax (Linnaeus, 1758) exposed to microplastics: Preliminary results. Environ. Pollut. 2016, 212, 251-256. [CrossRef]

44. Huang, J.; Wen, B.; Zhu, J.; Zhang, Y.; Gao, J.; Chen, Z. Exposure to microplastics impairs digestive performance, stimulates immune response and induces microbiota dysbiosis in the gut of juvenile guppy (Poecilia reticulata). Sci. Total. Environ. 2020, 733, 138929. [CrossRef]

45. Qiao, R.; Sheng, C.; Lu, Y.; Zhang, Y.; Ren, H.; Lemos, B. Microplastics induce intestinal inflammation, oxidative stress, and disorders of metabolome and microbiome in zebrafish. Sci. Total Environ. 2019, 662, 246-253. [CrossRef] [PubMed] 
46. Qiao, R.; Deng, Y.; Zhang, S.; Wolosker, M.B.; Zhu, Q.; Ren, H.; Zhang, Y. Accumulation of different shapes of microplastics initiates intestinal injury and gut microbiota dysbiosis in the gut of zebrafish. Chemosphere 2019, 236, 124334. [CrossRef]

47. Ni, J.; Wu, G.D.; Albenberg, L.; Tomov, V.T. Gut microbiota and IBD: Causation or correlation? Nat. Rev. Gastroenterol. Hepatol. 2017, 14, 573-584. [CrossRef]

48. Ouyang, M.; Feng, X.; Li, X.; Wen, B.; Liu, J.; Huang, J.; Gao, J.; Chen, Z. Microplastics intake and excretion: Resilience of the intestinal microbiota but residual growth inhibition in common carp. Chemosphere 2021, 276, 130144. [CrossRef] 